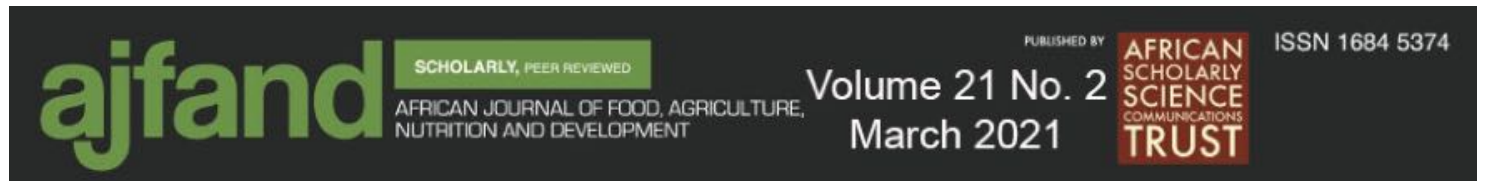

Afr. J. Food Agric. Nutr. Dev. 2021; 21(2): 17477-17491

https://doi.org/10.18697/ajfand.97.20150

\title{
EFFECTS OF TEMPERATURE, STEEPING TIME AND PARTICLE SIZE USED IN INFUSION BREWING ON TOTAL PHENOLIC CONTENT \\ AND ANTIOXIDANT ACTIVITY OF TEA PRODUCED FROM YOUNG UPLAND RICE LEAVES
}

\section{Uthai $\mathbf{N}^{1 *}$}

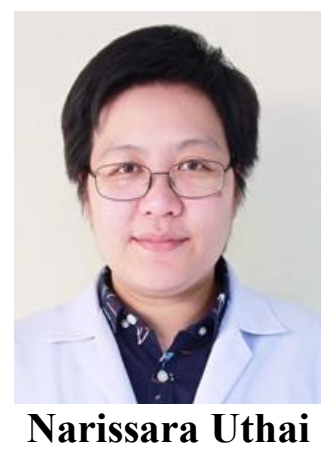

*Corresponding author email: narissara.u@mail.rmutk.ac.th

${ }^{1}$ Faculty of Home Economics Technology, Department of Food and Nutrition, Rajamangala University of Technology Krungthep, Bangkok, 10120, Thailand 


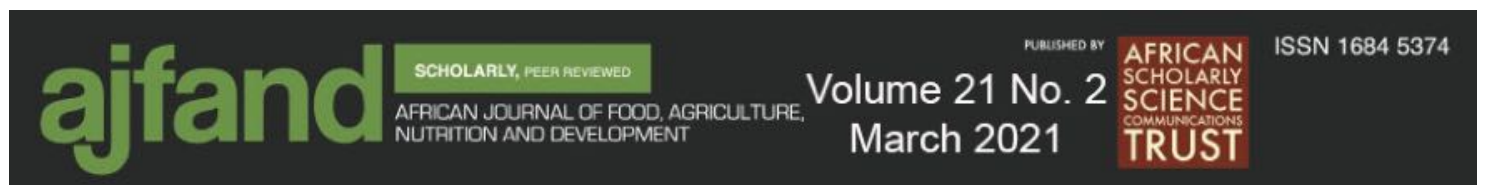

\begin{abstract}
Tea was brewed from young leaves of 4 weeks old Thai upland black waxy rice plants of the cultivar 'Damgatondam', which has a noticeable fragrant smell from both seeds and leaves. The plants were harvested about $1 \mathrm{~cm}$ above soil level, washed and cut into pieces, about $1 \mathrm{~cm}$ long. These pieces were then steamed for 1 min in a steamer rack, withering for $5 \mathrm{~min}$ by spreading them out in a thin layer, pan roasted at $70^{\circ} \mathrm{C}$ for 30 min and finally dried at $70^{\circ} \mathrm{C}$ for $90 \mathrm{~min}$. They were either kept as pieces of leaves or ground into a powder, and both were used for brewing tea by infusion in water at $4^{\circ} \mathrm{C}$, room temperature (about $25^{\circ} \mathrm{C}$ ), for $1,3,5,7,9,11$ or $15 \mathrm{~h}$ and brewing at $70^{\circ} \mathrm{C}$ or $98^{\circ} \mathrm{C}$ for $1,3,5,7,9,11$ or $15 \mathrm{~min}$. Directly after brewing, the tea was stored at $-25^{\circ} \mathrm{C}$ awaiting analysis. Each sample was analyzed for total phenolic content (TPC) and for antioxidant activity, by ferric reducing antioxidant power (FRAP), 2,2 diphenyl-1picrylhydrazyl (DPPH) and 2,2'-azino-bis (3-ethylbenzothiazo line-6-sulphonic acid) (ABTS) assays. Results showed that tea brewed from ground leaves had higher antioxidant activity than tea brewed from ungrounded leaves. The highest level of extraction was at $98^{\circ} \mathrm{C}$ for $15 \mathrm{~min}$, where the TPC was $62.79 \mathrm{mg} \mathrm{GAE} / 100 \mathrm{~g}$, antioxidant activity was 278.04 for DPPH, 195.38 for ABTS and $1150.13 \mathrm{mg}$ TE/100g for FRAP. Samples extracted at $4^{\circ} \mathrm{C}$ or room temperature also had high levels of TPC and antioxidant activity with the maximum extraction at room temperature for $15 \mathrm{~h}$; where TPC was $46.76 \mathrm{mg} \mathrm{GAE} / 100 \mathrm{~g}$, and antioxidant activities were 152.72 for DPPH, 140.42 for ABTS and $950.32 \mathrm{mg} \mathrm{TE} / 100 \mathrm{~g}$ for FRAP. Therefore, the level of extraction for tea brewed in all four conditions depended on both temperature and brewing time. Also, extraction of high levels of bioactive compounds depended on large surface areas of the leaves being in contact with water.
\end{abstract}

Key words: Antioxidant activity, total phenolic content, cold brewed, hot brew, 'Damgatondam' tea 


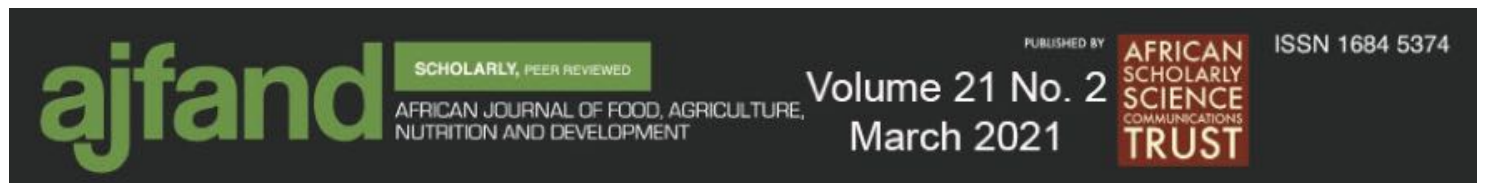

\section{INTRODUCTION}

Although there are increasing numbers and types of tea on sale throughout the world, most tea is made from leaves of either Camellia sinensis var. sinensis or $C$. sinensis var. assamica. There are various ways of processing tea, but the main types are green tea (non-fermented tea), oolong tea (semi-fermented tea) and black tea (fermented tea). In the processing of $C$. sinensis, green tea is produced by plucking young, first 2 or 3 leaves, and the apical bud, then steaming them as soon as possible after harvest to deactivate peroxidase enzymes that break down chlorophyll, followed by withering and heating to produce a dry staple product $[1,2]$. These processes conserve natural polyphenols and antioxidant activity more effectively than the fermentation involved in the manufacture of oolong and black tea, making them healthier. For example, there is a lower risk of cardiovascular disease, slower progress of cancer, enhanced insulin responsiveness and decreasing blood sugar levels from consuming green tea compared to oolong tea or black tea $[3,4]$.

The current work describes green tea made from young leaves of upland rice (Oryza sativa). There are many cultivars of rice, but 'Damgatondam', an upland black waxy rice cultivar grown in Chumpon province of Thailand, was selected due to the aroma of its seeds and leaves. Also, it contains comparatively high amount of protein, iron, and high antioxidant activity $[5,6]$.

Tea extraction is normally by brewing in boiling water. However, it has been shown that sometimes heating can deactivate or destroy some important heat sensitive bioactive compounds [7]. Previous research has shown that brewing methods including hot and cold brewing of green, oolong and black tea, as well as tea from other plants, can affect bioactive compounds. Hajiaghaalipou et al. [8] investigated brewing white, green and black tea (C. sinensis) at 28 or $100^{\circ} \mathrm{C}$ for 5 or $120 \mathrm{~min}$. They found that samples brewed for $5 \mathrm{~min}$ at $100^{\circ} \mathrm{C}$ had a higher total phenolic content and antioxidant activity (FRAP assay) than samples brewed at $28^{\circ} \mathrm{C}$ for $5 \mathrm{~min}$. However, brewing for $120 \mathrm{~min}$ at either 28 or $100^{\circ} \mathrm{C}$ resulted in similar levels of total phenolic content. Also, all the types of tea brewed for $120 \mathrm{~min}$ at $100^{\circ} \mathrm{C}$ had higher levels of antioxidant activity compared to those brewed for $120 \mathrm{~min}$ at $28^{\circ} \mathrm{C}$ except in green tea. Lantano et al. [9] also studied effects of brewing green, oolong and black teas ( $C$. sinensis) in cold and hot water, on the total phenols and antioxidant activity also using FRAP assay and found that the highest levels of total phenols and antioxidant activity were from cold brewing. Besides temperature, other factors can affect total phenolic compounds and antioxidant activity, including tea cultivar, soil, location in which they were grown, plucking method, and processing conditions. Uthai et al. [10] studied different amounts of rice leaves tea $(1 \mathrm{~g}, 1.5 \mathrm{~g}$ or $2 \mathrm{~g})$ brewed at 80,90 or $98^{\circ} \mathrm{C}$ for $3 \mathrm{~min}$. Their results showed that brewing $2 \mathrm{~g}$ of tea at $98^{\circ} \mathrm{C}$ for 3 min produced a beverage that was acceptable to consumers and also contained high levels of total phenols and antioxidant capacity. Damiani et al. [11] investigated brewing methods of tea from Rooibos (Aspalathus linearis) on antioxidant capacity, and found that tea brewed from both cold brewed (using room temperature water to brew then kept at $4^{\circ} \mathrm{C}$ ) and hot brewed (using $100^{\circ} \mathrm{C}$ water to brew then boiled it in microwave oven input power $1400 \mathrm{~W}$ for $5 \mathrm{~min}$ ) contained lower antioxidant capacity than tea from boiling water. 


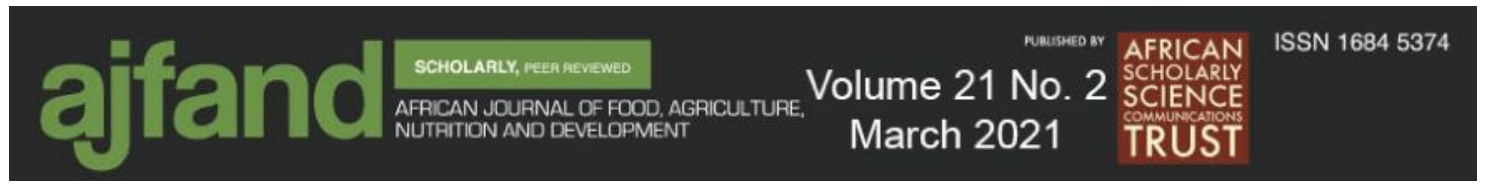

Since it has been shown that several factors, especially brewing temperature and time, can affect the quality of $C$. sinensis and other teas, it was decided to determine the effects of brewing conditions on the quality of 'Damgatondam' tea. The objective of this study was, therefore, is to determine the effects of temperature, steeping time and particle size on total phenolic content and antioxidant activity of tea brewed from upland rice leaves.

\section{MATERIALS AND METHODS}

\section{Chemicals and equipment}

All reagents, Trolox ( \pm 6$)$-hydroxy-2,5,7,8-tetramethylchroman-2 carboxylic acid), 2,2azino-bis (3-ethyl benzothiazoline-6sulfonic acid) diammonium salt (ABTS), 2,2 diphenyl-1-picrylhydrazyl (DPPH), 2,4,6-tripyridyl-s-triazine (TPTZ), Folin-Ciocalteu reagents, quaiacol, gallic acid monohydrate and iron (III) chloride hexahydrate were all purchased from Sigma Aldrich Corp., St. Louis, USA. For 96\% ethanol, 95.5\% methanol, sodium acetate trihydrate, acetic acid, potassium persulfate, hydrochloric acid and sodium carbonate the purchase source was Merck KGAA, Darmstadt, Germany. All reagents were of analytical grade. For preparation of the tea cultivar 'Damgatondam' bottled natural mineral water (Royal Orchid, Thai Airways International PLC, Bangkok, Thailand) from was used. Spectrophotometric measurements were carried out using a UV-Vis spectrophotometer (UV-1800, Shimadzu, Japan).

\section{Raw material and sample preparations}

The rice tea used in the experiments, 'Damgatondam', upland black waxy rice cultivar, was prepared using a modified method used for green tea processing. The plants were grown in Chumphon province of Southern of Thailand and harvested when they were 4 weeks old by cutting them about $1 \mathrm{~cm}$ above soil level. The plants were washed and cut it into pieces about $1 \mathrm{~cm}$ long. The processing was modified from a method used for green tea processing. Firstly, the leaves were steamed for $1 \mathrm{~min}$ to inhibit peroxidase activity, then withering by spreading on an aluminum tray in a thin layer at room temperature (about $25^{\circ} \mathrm{C}$ ) for $5 \mathrm{~min}$, pan roasting at $70^{\circ} \mathrm{C}$ for $30 \mathrm{~min}$ and dried in an electrical cabinet tray dryer at $70^{\circ} \mathrm{C}$ for $90 \mathrm{~min}$. Then, dried leaves were divided in 2 groups. A portion of the leaves was ground using a blender for $45 \mathrm{sec}$ at low speed until the particle size of leaves was about $1 \mathrm{~mm}$ long. The second portion was not ground with leaves having particle size of about $5 \mathrm{~mm}$ long.

The infusions of both unground pieces of leaves and ground leaves tea samples were prepared as follows: Samples were packed into tea bags containing $2 \mathrm{~g}$ of tea, and each sample was brewed in $150 \mathrm{~mL}$ of mineral water at room temperature $\left(25^{\circ} \mathrm{C}\right)$ or $4^{\circ} \mathrm{C}$, for $1,3,5,7,9,11,13$ or $15 \mathrm{~h}$ and brewing at 70 or $98^{\circ}$ for $1,3,5,7,9,11,13$ or $15 \mathrm{~min}$. After extraction, tea samples were filtered through Whatman No.4 filter paper and then the tea was immediately stored at $-20^{\circ} \mathrm{C}$ until the time of analysis (Figure 1A and 1B). Each sample was analyzed for total phenolic content (TPC) and antioxidant activity. Antioxidant activity was measured in three ways: ferric 


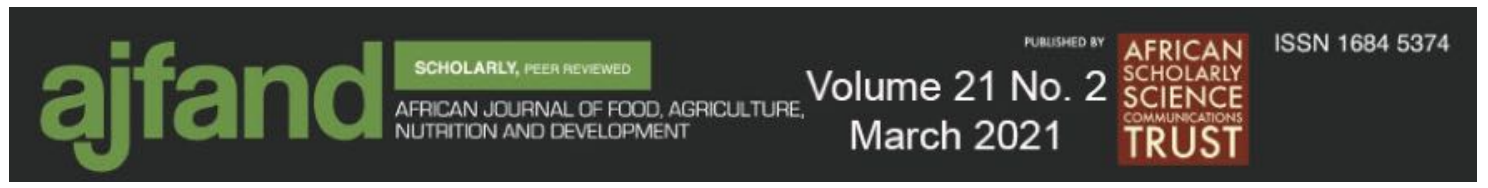

reducing antioxidant power (FRAP), 2,2 diphenyl-1-picrylhydrazyl assay (DPPH) and 2,2'-azino-bis (3-ethylbenzothiazo line-6-sulphonic acid) assay (ABTS).
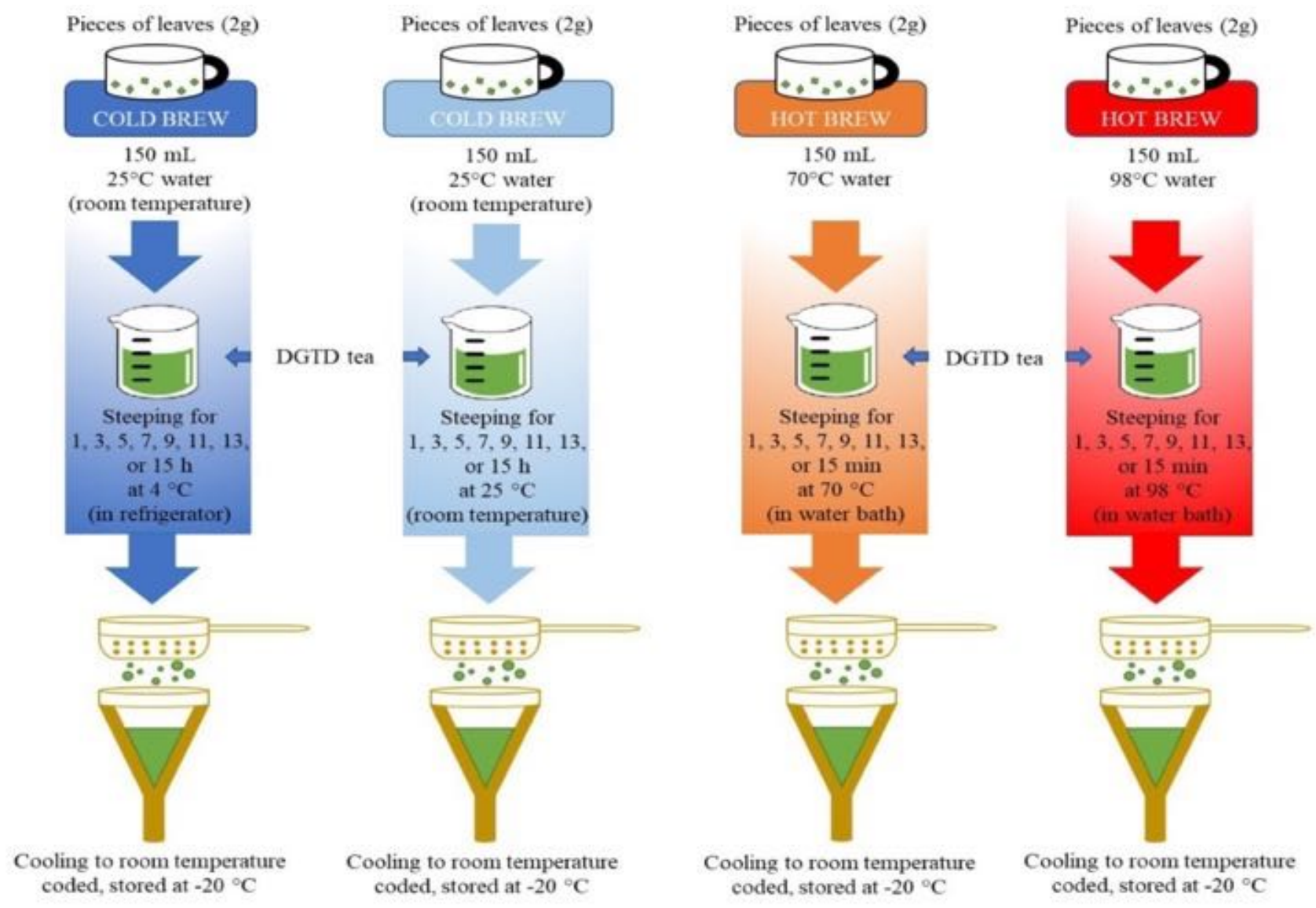

Figure 1A: A graphical outline of the four different brewing conditions used for 'Damgatondam' pieces of leaves tea preparation in the experiments 

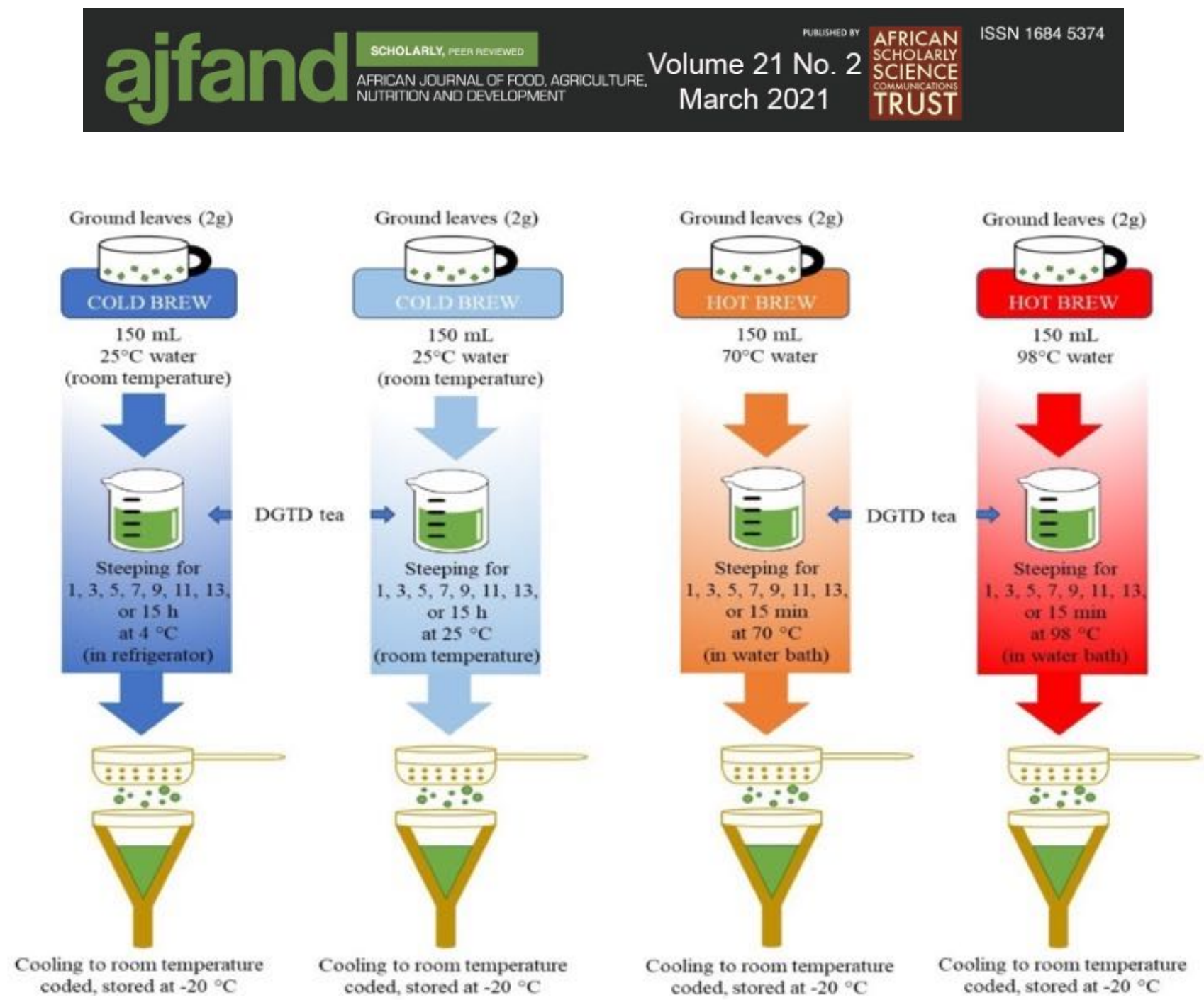

Figure 1B: A graphical outline of the four different brewing conditions used for 'Damgatondam' ground leaves tea preparation in the experiments

\section{Total phenolic content (TPC)}

The TPC was measured using the Folin-Ciocalteu procedure with some modifications [12] using a sample solution of Folin-Ciocalteu (diluted with distilled water in the ratio of 1:10), $1 \mathrm{M} \mathrm{Na}_{2} \mathrm{CO}_{3}$ and gallic acid solution (diluted with ethanol). First, a standard curve was prepared from gallic acid solution with 6 test tubes mixed with Folin-Ciocalteu solution and $1 \mathrm{M} \mathrm{Na}_{2} \mathrm{CO}_{3}$, and plotted at 0 (set blank by using distilled water), Folin-Ciocalteu solution and $1 \mathrm{M} \mathrm{Na}_{2} \mathrm{CO}_{3}$ ) at 50, 100, 150, 200 and $250 \mu \mathrm{M}$. Secondly, $0.5 \mathrm{~mL}$ of each sample was mixed well with Folin-Ciocalteu solution and $1 \mathrm{M} \mathrm{Na}_{2} \mathrm{CO}_{3}$. Next, all the test tubes were left for $15 \mathrm{~min}$ at room temperature $\left(25^{\circ} \mathrm{C}\right)$ in the dark and the absorbance was measured at $765 \mathrm{~nm}$ in a UV/Vis spectrophotometer (UV-1800 Shimadzu, Japan). The results were compared with the gallic acid standard curve and the results calculated as mg gallic acid equivalent per $100 \mathrm{~g}$ of sample (mg GAE/100g sample).

\section{Antioxidant capacity using Ferric reducing antioxidant power (FRAP assay)}

Analysis of antioxidant capacity, using FRAP assay used the procedure described by Wu et al. [13] with some modifications. The FRAP assay used 4 factors for the analyses: sample solution, $300 \mathrm{mM}$ acetate buffer solution (pH 3.6), TPTZ solution (diluted in $40 \mathrm{mM} \mathrm{HCl}$ ), $20 \mathrm{mM}$ ferric chloride solution and Trolox (diluted in 


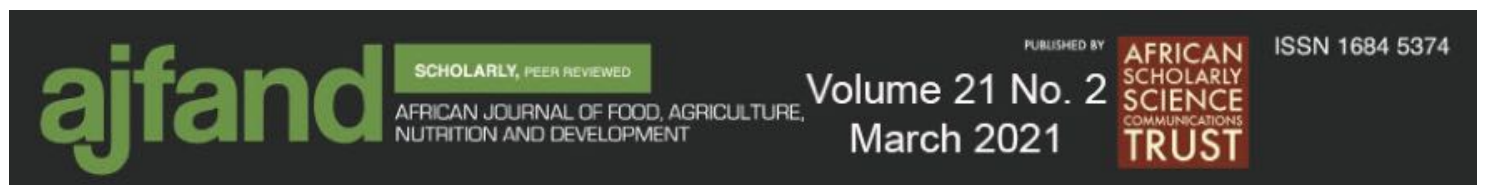

methanol). Ferric reducing antioxidant power (FRAP) solution was prepared by mixing $2.5 \mathrm{~mL}$ acetate buffer solution, $2.5 \mathrm{~mL}$ TPTZ solution and $2.5 \mathrm{~mL}$ ferric acid solution which contained in amber bottle, stirring well and leaving the FRAP solution for $30 \mathrm{~min}$ in water bath at $37^{\circ} \mathrm{C}$. Freshly prepared $2.85 \mathrm{~mL}$ of FRAP solution was mixed with $0.15 \mathrm{~mL}$ sample solution, kept at room temperature in the dark for $30 \mathrm{~min}$ and the standard curve of Trolox solution was calculated at 0 (set blank by using distilled water to replace sample solution), 40, 50, 100, 150, 300 and $500 \mu \mathrm{M}$ after that sample solution (stock solution). Absorbance was measured at $593 \mathrm{~nm}$ in a UV/Vis spectrophotometer (UV-1800 Shimadzu, Japan). The results were compared with the Trolox standard curve and calculated as mg Trolox equivalent per $100 \mathrm{~g}$ of sample (mg TE/100g sample).

\section{Antioxidant capacity using 2,2 diphenyl-1-picrylhydrazyl assay (DPPH assay)} The DPPH assay followed the procedure described by Wu et al. [13] was used with some modifications. $1.5 \mathrm{~mL}$ DPPH solution ( $0.15 \mathrm{mM}$ DPPH diluted in $95 \%$ ethanol) was reacted with sample solution in a test tube then left in the dark at room temperature for $30 \mathrm{~min}$. Trolox standard curve was plotted (set by mixing distilled water and methanol equally) at $0,10,20,30,50,70$ and $100 \mu \mathrm{M}$ for calculating the stock solution after measuring absorbance at $517 \mathrm{~nm}$ with UV/Vis spectrophotometer (UV-1800 Shimadzu, Japan). The results were compared with the Trolox standard curve reported in $\mathrm{mg}$ Trolox equivalent per $100 \mathrm{~g}$ sample (mg TE/100g sample).

\section{Antioxidant capacity using 2,2'-azino-bis (3-ethylbenzothiazoline-6-sulphonic acid) (ABTS assay)}

In the ABTS assay, the procedure described by Wu et al. [13] was used, with some modifications using a sample solution of $7.4 \mathrm{mM} \mathrm{ABTS}$ (diluted with deionized water), $2.6 \mathrm{mM}$ potassium persulphate solution (diluted with deionized water) and $1 \mathrm{mM}$ Trolox (diluted by methanol). Firstly, ABTS reagent was prepared by mixing ABTS solution and potassium persulphate solution (1:10), whose absorbance was measured at $734 \mathrm{~nm}$, and adjusted the absorbance by using $95 \%$ methanol for dilution until absorbance was $1.1 \pm 0.02$. The $2.85 \mathrm{~mL}$ of ABTS reagent was mixed with $0.15 \mathrm{~mL}$ sample solution in a test tube, vortexed and incubated in the dark at room temperature for $120 \mathrm{~min}$. A standard curve, was developed using the various concentrations at 0 (set at zero using methanol before calculating), 40, 50, 100, 150, 300 and $500 \mu \mathrm{M}$ (set by mixing with distilled water and ABTS reagent) of the standard (Trolox) prepared and their respective absorbance read at $734 \mathrm{~nm}$, with the aid of a UV-Vis spectrophotometer and values traced on the standard curve to obtain the antioxidant concentration, then the results were compared with the Trolox standard curve and reported in $\mathrm{mg}$ Trolox equivalent per $100 \mathrm{~g}$ sample (mg TE/100g sample).

\section{Data analysis}

The study used a completely randomized design and analyses of the samples were performed in triplicate. Analysis of variance (ANOVA) and the Duncan's New Multiple Range Test were used for mean comparisons at 95\% confidence level or $p \leq 0.05$, using SPSS. 


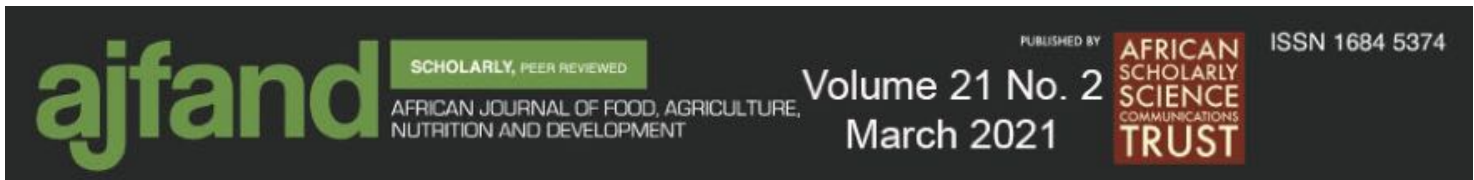

\section{RESULTS AND DISCUSSION}

The effect of different brewing conditions, temperature, steeping time and particle size (pieces of leaves and ground leaves) of 'Damgatondam' tea, at $4^{\circ} \mathrm{C}$ or room temperature (about $25^{\circ} \mathrm{C}$ ) for $1,3,5,7,9,11,13$ or $15 \mathrm{~h}$ and 70 or $98^{\circ} \mathrm{C}$ for $1,3,5,7$, $9,11,13$ or 15 min were determined. The result showed that all brewing conditions affected the level of TPC and antioxidant properties measured by FRAP, DPPH and ABTS assays, but the levels depended on extraction conditions (Figures 2, 3, 4 and 5).
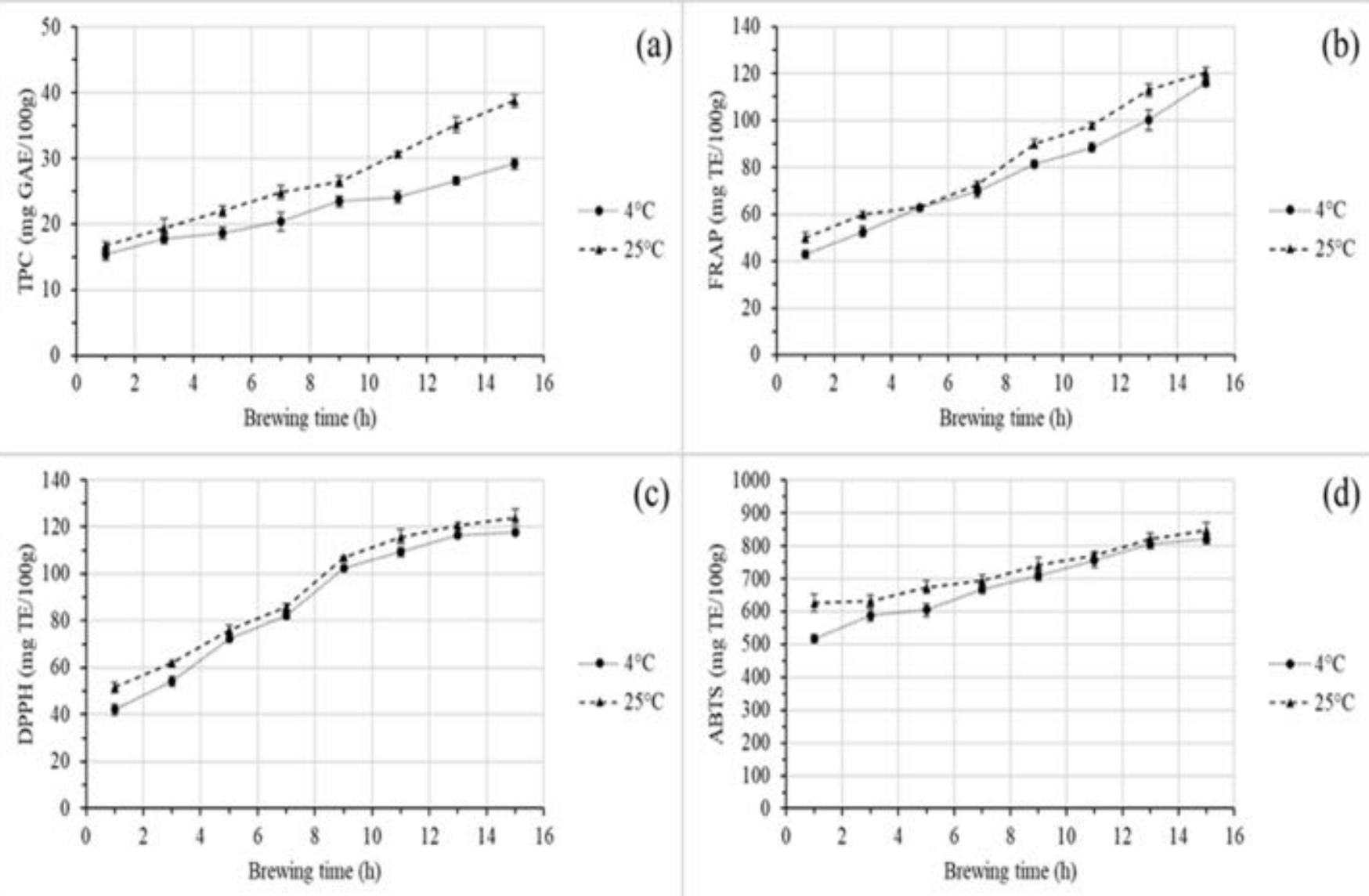

Figure 2: Total phenolic content (TPC) and antioxidant activity by FRAP, DPPH and ABTS assays in pieces of leaves 'Damgatondam' tea infusion (cold brewed) 

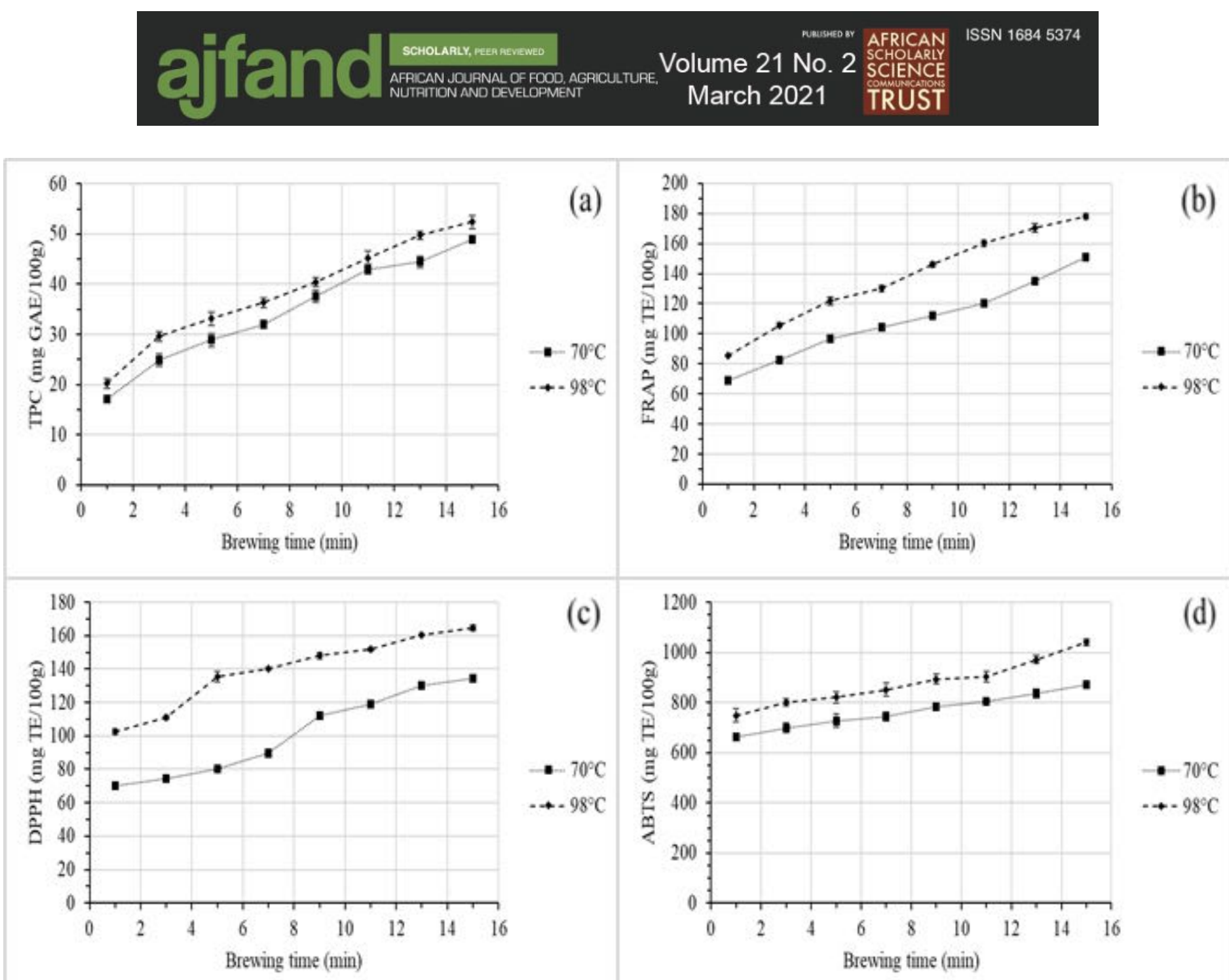

Figure 3: Total phenolic content (TPC) and antioxidant activity by FRAP, DPPH and ABTS assays in pieces of leaves 'Damgatondam' tea infusion (hot brewed) 

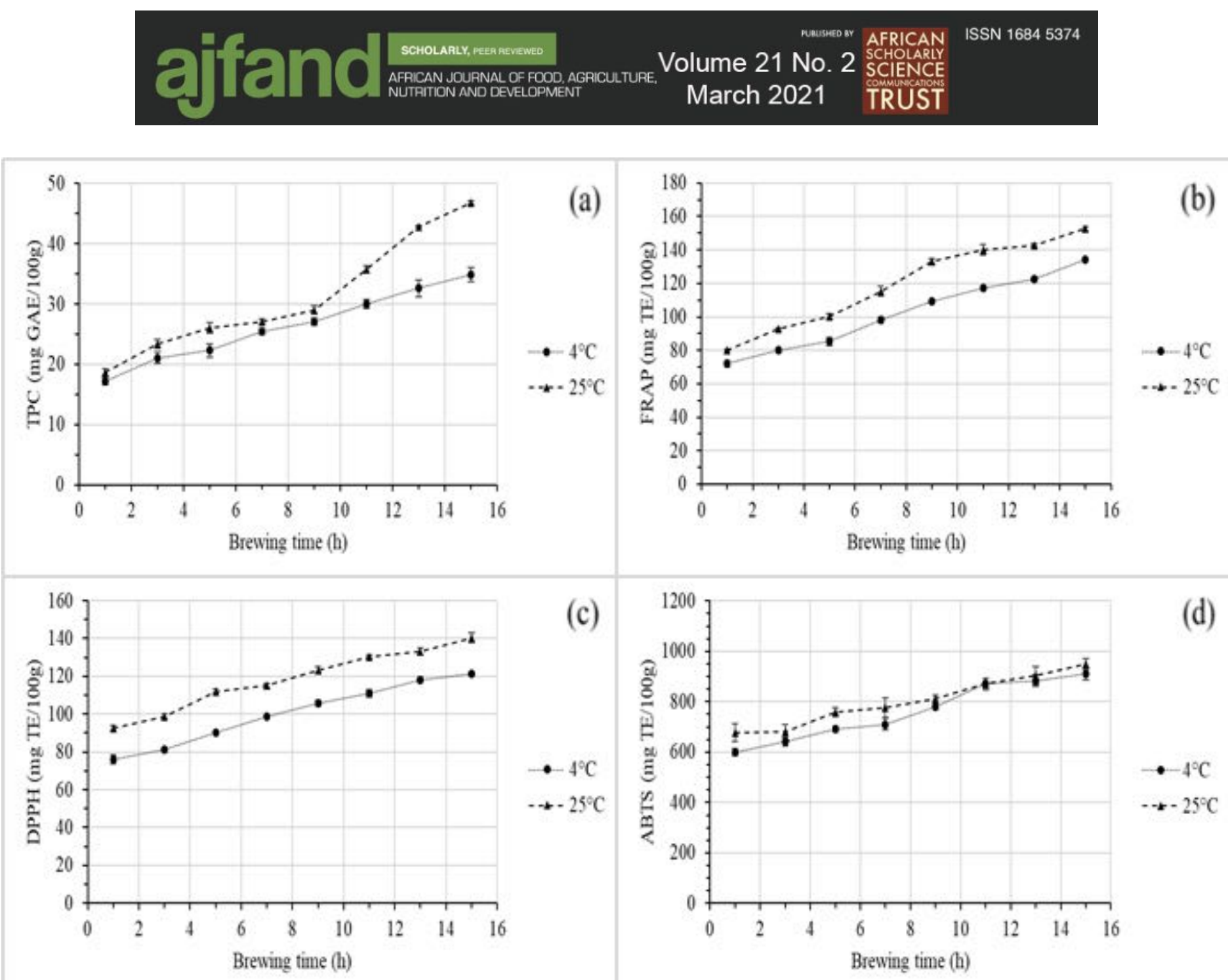

Figure 4: Total phenolic content (TPC) and antioxidant activity by FRAP, DPPH and ABTS assays in ground leaves 'Damgatondam' tea infusion (cold brewed) 

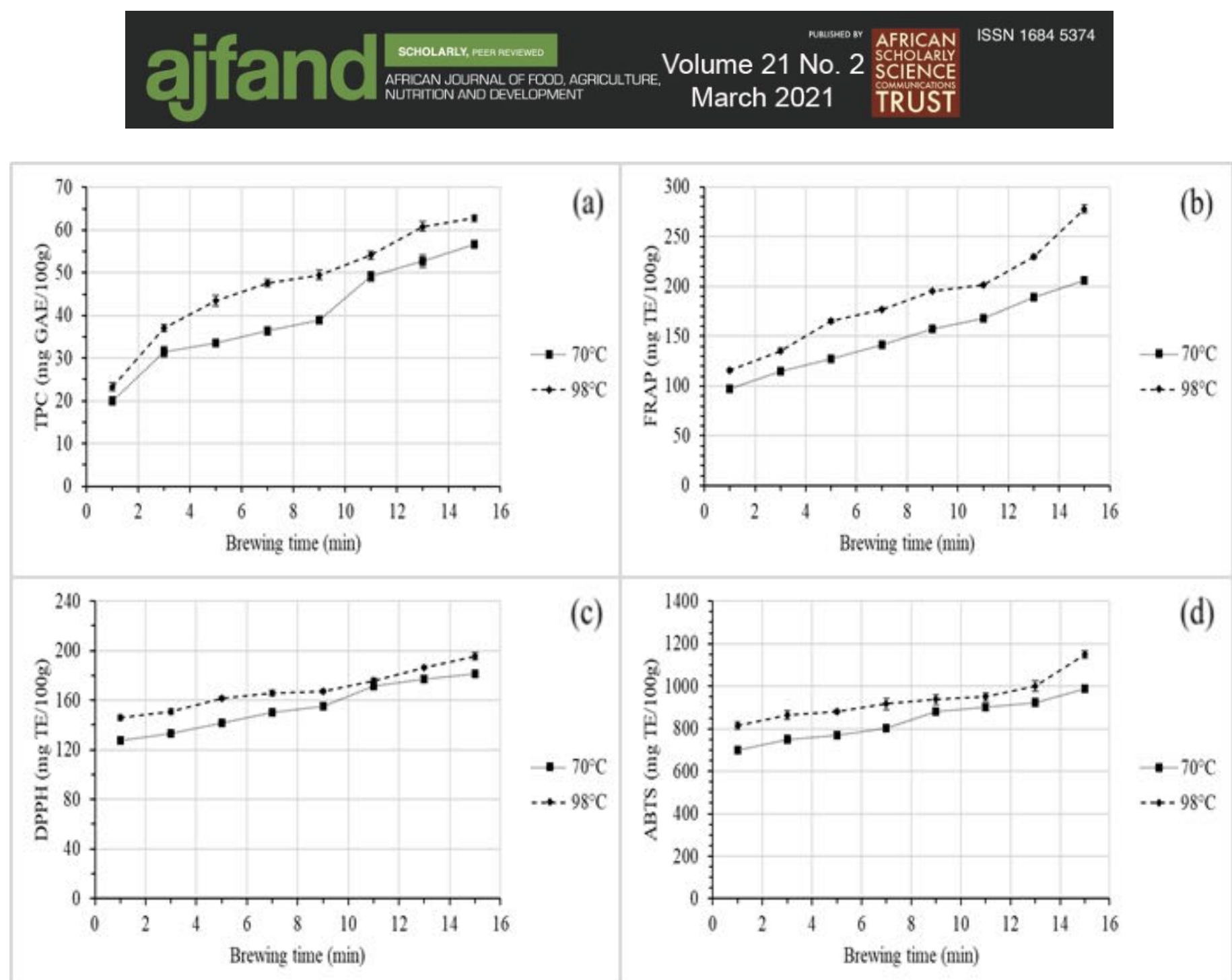

Figure 5: Total phenolic content (TPC) and antioxidant activity by FRAP, DPPH and ABTS assays in ground leaves 'Damgatondam' tea infusion (hot brewed)

\section{Effect of particle sizes (pieces of leaves and ground leaves) in 'Damgatondam' tea infusion on TPC and antioxidant activity}

The result showed the TPC levels and antioxidant activity (by FRAP, DPPH and ABTS assays) were always significantly ( $p \leq 0.05)$ higher in 'Damgatondam' tea infusions from ground leaves than from pieces of leaves (figures 2, 3, 4 and 5). The highest TPC and antioxidant activity were in ground leaves 'Damgatondam' tea infusion at $98^{\circ} \mathrm{C}$ for $15 \mathrm{~min}$, which were $62.79 \mathrm{mg}$ GAE/100g sample, 278.04, 195.38 and $1150.13 \mathrm{mg}$ $\mathrm{TE} / 100 \mathrm{~g}$ sample, respectively, while the lowest were from pieces of leaves at $4^{\circ} \mathrm{C}$ for 1 $\mathrm{h}$, at $38.80 \mathrm{mg} \mathrm{GAE} / 100 \mathrm{~g}$ sample, $120.31,124.10$ and $846.17 \mathrm{mg}$ TE/100g sample, respectively. Moreover, the ground leaves which were $1 \mathrm{~mm}$ long affected higher surface contact with water to extract than pieces of leaves which was $5 \mathrm{~mm}$ long. The effects of particle size confirmed the findings of Vuong et al. [14] who showed that the capability of scattering from milled leaves was always higher when compared with whole leaves tea, and that a leaf size about $1 \mathrm{~mm}$ long resulted in maximum catechin extraction especially when brewing in optimal temperature of water $\left(80^{\circ} \mathrm{C}\right)$. Also, particle size of leaves affected extraction differently, depending on water temperature. Lin et al. [15] also reported that the extraction at "hot max" was always higher than 


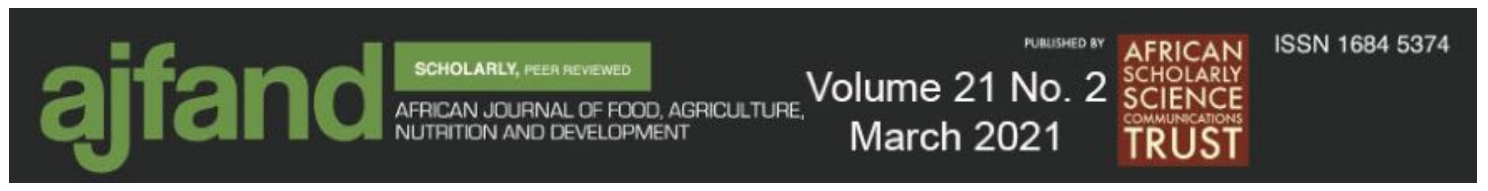

the "cold max" when the tea had been milled. These results were in conformity with the previous work of Castiglioni et al. [16] in green tea (Var. Salima Peony), compared milled leaf teas and whole leaf teas, both in hot $\left(70\right.$ and $\left.90^{\circ} \mathrm{C}\right)$ and cold (room temperature) brewed, their results indicating milled leaf tea brewed at $90^{\circ} \mathrm{C}$ for $7 \mathrm{~min}$, contained the highest amount of TPC and antioxidant activities, which was higher than whole leaf tea in all condition. Therefore, particle size of tea leaves, brewing temperature, and time for brewing affected extraction levels of TPC and antioxidant activity.

\section{Effect of temperature and time in 'Damgatondam' tea infusion on TPC and antioxidant activity}

The result showed the TPC levels and antioxidant activity (by FRAP, DPPH and ABTS assays) were significantly ( $p \leq 0.05)$ higher in 'Damgatondam' tea infusions prepared from higher temperature and longer time of brewing than the lower temperature and shorter time of brewing (figures 2, 3, 4 and 5). Ground leaves gave the highest level of TPC and antioxidant activity in all assays, with $98^{\circ} \mathrm{C}$ extraction for $15 \mathrm{~min}$, had 62.79 mg GAE/100g sample, 278.04, 195.38 and $1150.13 \mathrm{mg} \mathrm{TE} / 100 \mathrm{~g}$ sample, respectively. The highest values from cold brewed of ground teas extracted was from $25^{\circ} \mathrm{C}$ for $15 \mathrm{~h}$ giving $46.76 \mathrm{mg}$ GAE/100g sample, 152.72, 140.42 and $950.32 \mathrm{mg} \mathrm{TE} / 100 \mathrm{~g}$ sample, respectively. While pieces of leaves gave the highest level of TPC and antioxidant activity in all assays, with $98^{\circ} \mathrm{C}$ extraction for $15 \mathrm{~min}$, giving $52.39 \mathrm{mg} \mathrm{GAE} / 100 \mathrm{~g}$ sample, $178.08,164.54$ and $1040.89 \mathrm{mg} \mathrm{TE} / 100 \mathrm{~g}$ sample, respectively. The highest values from cold brewed teas extracted was from $25^{\circ} \mathrm{C}$ for $15 \mathrm{~h}$ giving $38.80 \mathrm{mg}$ GAE/100g sample, $120.31,124.10$ and $846.17 \mathrm{mg}$ TE/100g sample, respectively. The results confirmed greater bioactive compound content in 'Damgatondam' tea infusions prepared at the highest temperature and longest time as previously described by Pervauzunalic et al. [17], who studied different extraction methods of green tea (var. 'Fanning', 'Belas', 'China') at different extraction temperatures $\left(60,80,95\right.$ or $\left.100^{\circ} \mathrm{C}\right)$ and times (over the range of 5 to $240 \mathrm{~min}$ ). Their results indicated that the optimal condition was brewed at $100^{\circ} \mathrm{C}$ for $240 \mathrm{~min}$. Also, Komes et al. [18] reported brewing green tea at 60,80 or $100^{\circ} \mathrm{C}$ affected total phenolic content and antioxidant activity, with the highest temperature giving the higher total phenolic content. In addition, when the tea leaves were steeped at 4 and $25^{\circ} \mathrm{C}$ (room temperature) several times, the antioxidant activity increased with increasing time and became comparable with the hot extraction. All cold brewed teas gave lower antioxidant activity than all hot brewed with the same brewing time. Castiglioni et al. [16] reported that green tea (Lung Ching) brewed at room temperature for 15, 30, 60 and 120 min resulted in increased TPC with increasing steeping time. Ramirez-Aristizabal et al. [19] compared the effects of brewing temperature $\left(25\right.$ or $\left.80^{\circ} \mathrm{C}\right)$ of green tea on antioxidant capacity and showed antioxidant capacity was lower at lower temperature. These findings indicate that the cold brewed treatment effects on TPC and the antioxidant activity levels required more time for the bioactive compounds in the leaves to be released, while hot water brewing resulted in faster extraction and a greater release of bioactive substances in a shorter time. 


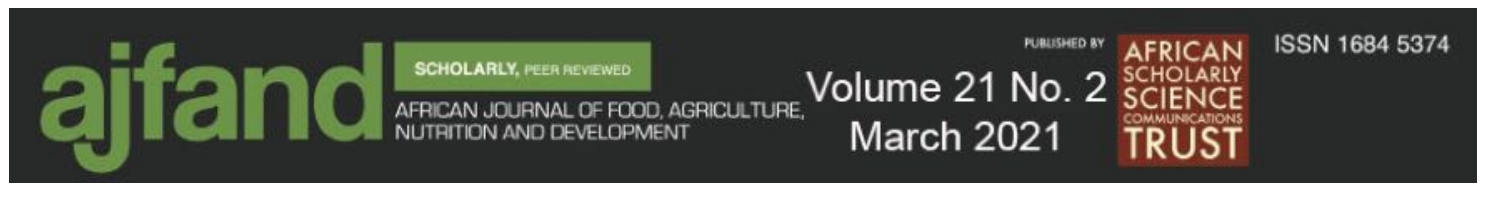

\section{CONCLUSION}

The conditions tested for optimum total phenolic content and antioxidant activity from 'Damgatondam' tea infusion were particle size of the leaves, temperature and steeping time. Results showed that ground leaves, extracted by the highest temperature $\left(98^{\circ} \mathrm{C}\right)$ and longest time $(15 \mathrm{~min})$ gave the highest extraction of total phenolic content and antioxidant activity. Cold brewing tea resulted in lower total phenolic content and antioxidant activity but ground leaves at $25^{\circ} \mathrm{C}$ for $15 \mathrm{~h}$ gave the best results of those tested (at 4 and $25^{\circ} \mathrm{C}$ ). The consumers and tea producers could use the information from this study to prepare tea either hot or cold brewed in order to optimize its nutritional benefits. 


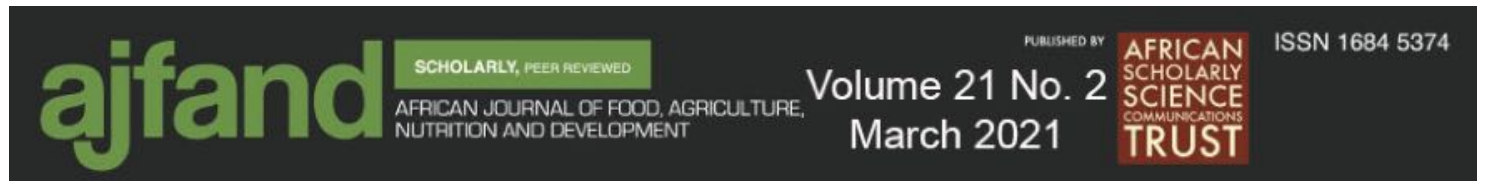

\section{REFERENCES}

1. Chan EW, Soh EY, Tie PP and YP Law Antioxidant and antibacterial properties of green, black, and herbal teas of Camellia sinensis. Pharmacognosy Res. 2011; 3(4): 266-272.

2. Singh V, Verma DK and G Singh Processing technology and health benefits of green tea. Popular Kheti. 2014; 2(1): 23-30.

3. Ogunleye AA, Xue F and KB Michels Green tea consumption and breast cancer risk or recurrence: A meta-analysis. Breast Cancer Res Treat. 2010; 119(2): 477-484.

4. Liu K, Zhou R, Wang B, Chen K, Shi LY, Zhu JD and MT Mi Effect of green tea on glucose control and insulin sensitivity: a meta-analysis of 17 randomized controlled trials. Am. J. Clin. Nutr. 2013; 98(2): 340-348.

5. Nokkoul R Thai upland rice; black waxy rice 'Damgatondam' cultivar (In Thai). http://upland-rice.blogspot.com/2016/03/upland-rice.html/ (Accessed 29 May 2019).

6. Uthai N, Thamakorn P, Kerdpiboon $\mathbf{S}$ and $\mathbf{R}$ Nokkoul Process optimization, antioxidant activity and sensory characteristics of green tea made from young fragrant rice leaves cultivar Damgatondam. Afr. J. Food Agric. Nutr. 2019; 19(4): 14950-14970.

7. Das $\mathbf{C}$ and $\mathbf{S}$ Chatterjee Evaluation of antioxidant status in cold brewed tea with respect to hot decoction: comparative study between green and black varieties. Int. J. Pharmacogn. Phytochem. 2017; 9(7): 961-964.

8. Hajiaghaalipour $\mathbf{F}$, Sanusi $\mathbf{J}$ and MS Kanthimath Temperature and time of steeping affect the antioxidant properties of white, green and black tea infusions. J. Food Sci. 2016; 81(1): 246-254.

9. Lantano C, Rinaldi M, Cavazza A, Barbanti and C Corradini Effect of alternative steeping methods on composition, antioxidant property and colour of green, black and oolong tea infusion. J. Food Sci Technol. 2015; 52(12): 82768283.

10. Uthai N, Thamakorn $\mathbf{P}$ and $\mathbf{R}$ Nokkoul Effect of the preparation and brewing methods on the bioactive compounds and sensory evaluation of upland rice (Oryza sativa L. cv. Ka Ton Dam) grass tea. In: Proceeding of the 4th Food and Applied Bioscience, Chiang Mai, Thailand. 2018; 96-104.

11. Damiani E, Carloni P, Rocchetti G, Senizza B, Tiano L, Joubert E, Beer D and $L$ Lucini Impact of cold versus hot brewing on the phenolic profile and antioxidant capacity of Rooibos (Aspalathus linearis) herbal tea. Antioxidants. 2019; 8(10): 1-19. 


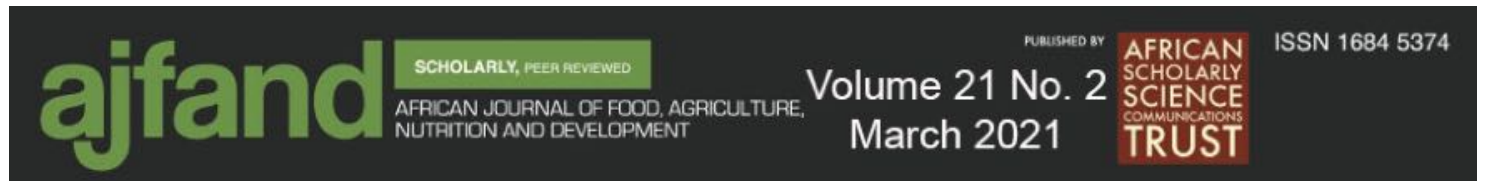

12. Yun P, Thamakorn $\mathbf{P}$, Nokkoul R, Suwapanich $\mathbf{R}$ and $\mathbf{K}$ Huangrak

Antioxidant activity and bioactive compounds of freeze-dried product from Thai upland rice grass juice. In: Proceeding of the 17th Food Innovation Asia Conference, Innovative ASEAN Food Research towards the World, Bangkok, Thailand. 2015; 35-41.

13. Wu HC, Chen HM and CY Shiau Free amino acids and peptides as related to antioxidant properties in protein hydrolysates of mackerel (Scomber austriasicus). Food Res Int. 2003; 36(9-10): 949-957.

14. Vuong QV, Golding JB, Stathopoulos CE, Nguyen MH and PD Roach Optimizing conditions for the extraction of catechins from green tea using hot water. J Sep Sci. 2011; 34(21): 3099-3106.

15. Lin SD, Liu EH and JL Mau Effect of different brewing methods on antioxidant properties of steaming green tea. LWT-Food Sci Technol. 2008; 41(9): 1616-1623.

16. Castiglioni S, Damiani E, Astolfi P and P Carloni Influence of steeping conditions (time, temperature, and particle size) on antioxidant properties and sensory attributes of some white and green teas. Int J Food Sci Nutr. 2015; 66(5): 491-497.

17. Perva-Uzunalic A, Skerget M, Knez Z, Weinreich B, Otto F and S Gruner Extraction of active ingredients from green tea (Camellia sinensis): Extraction efficiency of major catechins and caffeine. Food Chem. 2006; 96(4): 597-605.

18. Komes D, Horzic' D, Belscak A, Ganic' KK and I Vulic' Green tea preparation and its influence on the content of bioactive compounds. Food Res Int. 2010; 43(2010): 167-176.

19. Ramirez-Aristizabal LS, Ortiz A, Restrepo-Aristizabal MF and JF SalinasVillada Comparative study of the antioxidant capacity in green tea by extraction at different temperatures of four brands sold in Colombia. VITAE, Revista de la Facultad de Ciencias Farmacéuticas y Alimentarias. 2017; 24(2): 132-145. 